\title{
Anabases
}

ANABASES Traditions et réceptions de l'Antiquité

$26 \mid 2017$

Varia

\section{Bénédicte COUDIÈRE, La truelle et le phylactère. La proximité des images}

Mathieu Scapin

\section{OpenEdition}

Journals

Édition électronique

URL : http://journals.openedition.org/anabases/6251

DOI : 10.4000/anabases.6251

ISSN : 2256-9421

Éditeur

E.R.A.S.M.E.

Édition imprimée

Date de publication : 1 novembre 2017

Pagination : 231-232

ISSN : 1774-4296

Référence électronique

Mathieu Scapin, «Bénédicte coudière, La truelle et le phylactère. La proximité des images 》, Anabases [En ligne], 26 | 2017, mis en ligne le 01 novembre 2017, consulté le 19 janvier 2021. URL : http:// journals.openedition.org/anabases/6251 ; DOI : https://doi.org/10.4000/anabases.6251

Ce document a été généré automatiquement le 19 janvier 2021.

(c) Anabases 


\title{
Bénédicte COUDIÈRE, La truelle et le phylactère. La proximité des images
}

\author{
Mathieu Scapin
}

\section{RÉFÉRENCE}

Bénédicte COUDIÈRE, La truelle et le phylactère. La proximité des images, Talence, Fédora, Collection Détourages, 2017, 229 p. 28 euros / ISBN 979-10-96137-04-6.

1 Voilà maintenant quelques années que la réception de l'Histoire dans les médias suscite un intérêt grandissant. Si le spectre de l'Antiquité a déjà été balayé et continue de l'être, c'est au tour du Moyen Âge et des époques modernesd'attirer l'attention des scientifiques.

2 Le pari de la jeune maison d'éditions FEDORA est de proposer aux archéologues ou aux passionnés d'archéologie des ouvrages que l'on ne trouve pas forcément dans les librairies: dictionnaire du vocabulaire technique français-anglais, réflexion sur les limites chronologiques de l'archéologie intitulée Du silex au gobelet en plastique,ouencore l'ouvrage qui fait l'objet du présent compte rendu.

3 La collection « Détourages » est dédiée aux liens qu'entretiennent l'archéologie et les médias contemporains (BD, cinéma, jeux vidéos par exemple). C'est dans le cadre de cette intermédialité que Bénédicte Coudière, journaliste et chroniqueuse du $9^{\mathrm{e}}$ art s'est intéressée à l'image de l'archéologue dans la bande dessinée. L'originalité de cet ouvrage ne réside pas dans le sujet mais dans le choix de l'auteure, non spécialiste, bien que titulaire d'une licence en histoire de l'art. Et c'est la faiblesse de l'ouvrage qui se rapproche bien plus d'une critique géante de titres juxtaposés les uns derrière les autres, que d'une réelle recherche sur l'image de l'archéologue et de l'archéologie dans la $\mathrm{BD}$. Le travail de réception est un des plus exigeants en Histoire et le manque de méthode d'analyse pénalise l'auteure, qui propose un plan en deux parties trop confus et décousu. 
4 L'ouvrage est partagé en trois moments, une longue introduction et deux parties. L'introduction passe rapidement sur l'histoire de la BD et introduit l'idée du voyage dans le temps par le découpage, bien discutable, des différents genres dans lesquels elle peut prendre place. La première partie intitulée « Revivre le passé et combler les blancs par les bulles " présente quelques titres investissant les vides historiques grâce à la science-fiction. En rapprochant régulièrement les auteurs de BD et l'archéologie, B. Coudière ne rend pas compte du travail de l'archéologue et de l'archéologie que ce soit dans le réel ou dans les fictions.

5 Il est intéressant de remarquer qu'elle navigue souvent entre Archéologie et Histoire lorsqu'il s'agit de titres qui ne traitent pas d'Antiquité, comme si l'archéologie était l'apanage d'une seule période. C'est notamment le cas lorsqu'il est question du Moyen Âge ou de la Renaissance, affublée de son lot de poncifs tout aussi bien applicable à l'Antiquité ou au Moyen Âge (p. 101 «chamboulement aussi bien intellectuel que politique. C'est le temps des complots, des nuits sanglantes, des alliances, de certaines guerres emblématiques »). Dans cette partie comme dans le reste de l'ouvrage, chacun à leur tour, l'Historien est archéologue et l'Archéologue est historien, selon les besoins de la période étudiée.

6 La seconde partie nommée "La bande dessinée comme outil de transmission» s'intéresse à un aspect intéressant de la bande dessinée mais tourne autour de l'Antiquité comme seule valeur étalon de l'archéologie. Malheureusement, la complexité du sujet et le manque de clarté rend l'ensemble trop confus. L'on passe des quizz de l'INRAP au guide de fouilles en bande dessinée à l'histoire de l'Humanité ; le peu d'exemples d'illustrations peine à dérouler une démonstration convaincante. L'auteure s'intéresse ensuite à la bande dessinée dans les musées, sans que l'on comprenne véritablement pourquoi (avec une étude de l'onglet boutique du musée du Louvre!), alors que le sujet mériterait un travail entièrement dédié ; les liens avec l'archéologie ont complètement disparu, sauf la maigre sous-partie traitant des expositions de bandes dessinées dans les musées (Ave Alix, Astérix à Alesia ou Hergé au Grand Palais) qui aurait largement réclamé une partie à elle seule.

7 L'épilogue est bien plus lucide que le propos développé pendant les 200 pages: « il est impossible d'être ici exhaustif (...) il n'y a pas de fin, pas de conclusion acceptable (p. 217)».

8 Le thème abordé relève de plusieurs travaux de thèse, construits avec méthode et critique scientifique. On notera la présence discrète du manga qui a pourtant sa place dans le sujet; pour s'en convaincre, on conseille au lecteur des titres comme Thermae Romae ou Ad Astra, accompagnés de la démarche de création des auteurs nippons, rendant compte de leur vision de l'histoire romaine et de sa restitution.

9 Le véritable intérêt de cet ouvrage réside dans les interviews d'auteurs de BD et la présence de planches en couleurs, pourtant peu utilisées pour le propos de l'auteure. 


\section{AUTEURS}

\section{MATHIEU SCAPIN}

Université Toulouse - Jean Jaurès (UT2J) Musée Saint-Raymond mathieu.scapin@gmail.com 